\title{
Roteiro turístico dominicano em Amarante e em Baião (Norte de Portugal)
}

\author{
José Carlos Meneses Rodrigues* \\ Instituto de Estudos Superiores de Fafe (Portugal)
}

\begin{abstract}
Resumo: As ordens religiosas primaram pela qualidade na busca de lugares para conjuntos monásticos, em nome da fé, cultura e agregação de populações. A rota incide em templos de raiz dominicana (S. Gonçalo e S. Domingos, Amarante) e na absorção de outros (Mancelos e Freixo de Baixo, Amarante, e Ancede, Baião). Em Amarante, a arte obedece à tratadística das diferentes fases estilísticas dos melhores artistas das escolas do Porto e de Braga. Vislumbram-se estilos do maneirismo ao neoclássico. Objetivos: associar a rota às potencialidades da região - turismo gastronómico, cultural e de natureza, às boas acessibilidades e condições de alojamento e ao entrosamento na Rota do Românico do Tâmega e Sousa e Douro Sul. Como argumento de rota, a metodologia baseou-se na literatura do autor e de investigadores com elos nas estirpes da arte e do turismo religioso, havendo lugar, posteriormente, a um trabalho com inquérito, sublinhado na conclusão.
\end{abstract}

Palavras-chave: Turismo; Rota; Arte; Dominicanos; Desenvolvimento.

\section{The Dominican route as a tourist attraction in Amarante and Baião (North of Portugal)}

Abstract: Religious orders have always attemped to seek out strategic places for their convents and monasteries as a way of ensuring spreading the faith and culture to as broad as possible a segment of the population. The route includes mainly the Dominican order's monasteries and convents in S. Gonçalo and S. Domingos, Amarante but also others (in Mancelos and Freixo de Baixo, Amarante, and Ancede, Baião). In Amarante, the art adorning the buildings is a faithful reflection of the various different phases of artistic creation in Porto and Braga., from Mannersim through to Neoclassical. The aim here is to associate the route with the potential of the region - gastronomic, cultural and nature tourism with accommodation, all of which are easily accessible and link in to the Romanesque Art Route of Tâmega e Sousa and Douro Sul. To argue for the validity of the route, the methodology was based on the reseach literature of the author and fellows with respect to styles in art and religious tourism, followed by a field study that is, emphasized in the conclusion.

Keywords: Tourism; Route; Art; Dominicans; Development.

\section{Introdução}

Sugerimos um percurso entre Amarante [Mancelos, Freixo de Baixo, Cidade (S. Gonçalo, S. Domingos, Museu de Arte Sacra)] e Baião (Ancede - igreja e capela de N. S. ${ }^{a}$ do Bom Despacho), com influências artísticas eruditas e periféricas. Os templos de S. Gonçalo e de S. Domingos são os únicos de raiz dominicana; os restantes são absorvidos pela influência dos dominicanos junto do poder régio. Nesta rota transcorre a arquitectura (românico, gótico, renascimento, maneirismo e barroco) e a talha, onde pontuam o maneirismo, o barroco nacional e joanino, o rococó, o neoclássico e espécimes "ao estilo". De construções feitas para a "glória de Deus", hoje passam a ter mais um estatuto: atrações de um turismo religioso emergente que, em Portugal, tem carácter de sustentabilidade. A Igreja, o Estado (pela via das regiões de turismo, Porto e Norte, no caso), as instituições de ensino público e privado dos ensinos secundário e superior, as empresas (Turel, em Braga, é um bom exemplo), as rotas já instituídas e em estudo (a do Românico no Vale do Sousa, Tâmega e Douro Sul), os poderes locais, os investigadores e as comunidades de cada núcleo em estudo são fundamentais para o seu desenvolvimento.

Professor; E-mail: meneses.jc@gmail.com 
Aos templos de raiz dominicana (S. Gonçalo e S. Domingos, em Amarante) aditam-se os que foram absorvidos pelos dominicanos: Mancelos e Freixo de Baixo, em Amarante, e mosteiro de Ancede, em Baião. No Museu de Arte Sacra, contíguo à igreja de S. Domingos, recai uma motivação acrescida: arquitetura, talha, pintura e escultura, que obedecem à tratadística das diferentes coordenadas estilísticas interpretadas pelos melhores artistas das épocas e religam-se às escolas artísticas do Porto e de Braga - do renascimento (residual) ao neoclássico. A escola artística de Amarante tem também o seu contributo, principalmente através dos seus pintores.

Os visitantes têm a oportunidade de apreciar o vulto da Ordem Dominicana no campo artístico, numa região periférica com exemplos do melhor da época e da envolvência regional. A iconografia é objeto da nossa atenção, nomeadamente o programa dominicano: S. Francisco no lado do Evangelho e S. Domingos no lado da Epístola, nos retábulos-mores; a inversão verifica-se nos templos franciscanos.

Para o efeito, desenhámos objetivos: i) compreender as particularidades do turismo religioso numa combinação coerente com cultura, lazer e tempo livre; ii) identificar as acessibilidades e as condições de alojamento (hotelaria, alojamento local, casas de campo, agroturismo, turismo de aldeia, hotel rural); iii) reconhecer as potencialidade existentes na região agregadas ao turismo gastronómico (com evidência para o vinho verde), cultural (casas de Pascoaes, Amarante, e de Tormes, Baião, onde funciona a Fundação Eça de Queirós, artesanato), de natureza (pedestrianismo, serras, rios, desportos de aventura, ao ar livre, BTT), entre outros; iv) enquadrar a rota nas oportunidades oferecidas pelo rio Douro; v) valorizar a rota na arquitetura da RR (Rota do Românico do Tâmega e Sousa e parte do Douro Sul - Cinfães e Resenda), que abraça um espólio de castelos, torres senhoriais, pontes, memoriais, mosteiros, igrejas e capelas. Realçar os caminhos da fé locais e regionais e do caminho de Santiago de Compostela.

Quanto à metodologia, as intervenções e o conhecimento cada vez mais amplo dos templos em causa, designadamente os incluídos na RR - conduziram-nos ao estabelecimento de uma proposta de rota. A pesquisa bibliográfica (incluindo os nossos estudos) e a contextualização dos temas abordados, generalizando-se a rota para turistas e peregrinos, constituíram o fundamento do nosso estudo.

Não está fora de propósito a realização de um inquérito online e, ou, entrevistas, aos representantes da TPNP (Turismo do Porto e Norte de Portugal), da DRCN (Direção Regional da Cultura do Norte), da RR (Rota do Românico do Tâmega e Sousa e Douro Sul), das associações de desenvolvimento, da CIM (Comunidade Intermunicipal) Tâmega e Sousa, clero, autarcas, técnicos de turismo e população dos locais em estudo, das unidades hoteleiras e do TER (Turismo no Espaço Rural), da restauração, das empresas de animação e das agências de viagens.

\section{Mendicantes: uma relação notável na história religiosa de Portugal}

O terramoto de 1755 arruinou a igreja de S. Domingos, em Lisboa; em 1768, D. José dava a antiga fachada da igreja patriarcal para a igreja de São Domingos, que ainda hoje se conserva. Os estudos não puderam ser retomados com as sucessivas leis contra as ordens religiosas: os frades iam diminuindo em número até à extinção definitiva, em 1834, passando a igreja a Paróquia de Santa Justa e Santa Rufina. A presença dominicana em Lisboa ficou reduzida à igreja do Corpo Santo - Padres Irlandeses - e do Convento e Colégio do Bom-Sucesso (Carreira, s.d.).

Os dominicanos só voltaram a Lisboa com o Colégio "Clenardo" (1947-1968), abrindo-se, no ano seguinte, a residência Santa Filomena com o auxílio dos dominicanos canadianos. O novo convento de S. Domingos de Lisboa reabre em 1994, sucessor no tempo ao antigo convento de S. Domingos (Carreira, s.d.).

Voltemos ao golpe de 1834: A. Herculano, depois de profetizar que caísse em pó o mosteiro, e maldito o que erguê-lo intentar redime-se, mais tarde, qualificando a extinção das ordens de uma realidade das mais torpes, mais ignominiosas, mais estúpida e cobardemente cruéis do século presente...sentenciando: Aqui jaz a última era dos mártires (Rolo, 2000: 87). O último provincial regista uma estatística de 1833, observando que apesar dos danos graves já sofridos pelo rebentar da procela ainda residiam nos conventos 242 religiosos ou, ao todo, uns 250 (Rolo, 2000: 87). Os dominicanos levam uns 770 anos contínuos na história religiosa de Portugal desde a chegada de Frei Soeiro Gomes a Montejunto, em 1217. Pelo ramo feminino, regista-se, em 1894 (Rolo, 2000: 87), a última freira de quatro cenóbios antigos.

A Ordem Franciscana ou dos Frades Menores nasce a par da Dominicana, originando, com a Carmelita, as ordens mendicantes (Vieira \& Lacerda, 2010). A propagação da Ordem dos Frades Menores marca a espiritualidade das populações urbanas medievais portuguesas. Aos franciscanos, dominicanos e agostinhos foi confiado o cargo de confessores de el-rei até à morte de D. Manuel I (1469-1527), antes do aparecimento dos jesuítas na Corte. Na pobreza do vestir, na frugalidade do viver e na atitude de vida, 
tiveram entrada em todos os estratos sociais, incluindo a Corte. A partir de D. João III (1502-1557), ao longo de duzentos anos, a consciência dos reis foi entregue aos jesuítas (Marques, 1993: 54).

Os dominicanos, com todas as suas estruturas de formação humana, cultural, doutrinal e religiosa dos seus membros desenvolveram uma fecunda ação missionária em toda a costa índica da África Oriental, desde a Ásia até à China e, para o sul, no Pacífico, até à descoberta e pregação em Timor. Em meados do século XVII, há mais de 500 dominicanos no Oriente e, no primeiro quartel do século XVIII, a estatística sobe para 700 (Rolo, 2000: 86). Ajudaram, desde o início, a construir a história religiosa de Portugal. Não foram indiferentes à proteção dos infantes: Frei João Viterba, confessor de D. Pedro, foi a inspiração do Leal Conselheiro, de D. Duarte (Rolo, 2000: 82). Os estudos da Ordem de Bolonha, Colónia, Lovaina, Paris e Salamanca criaram um património cultural herdado, principalmente nas escolas de Lisboa, Batalha e Coimbra (Rolo, 2000: 83).

Fr. Bartolomeu dos Mártires, na época tridentina, foi o primeiro dominicano da história religiosa pela heroicidade das virtudes, teologia espiritual de vanguarda, paradigma confesso de S. Carlos Borromeu. Infatigável visitador das igrejas, de largo impacto sócio-caritativo pela atribuição de bolsas de estudo, dotes de casamento e de profissão religiosa, importação de pão e panos baratos de Inglaterra para vestir pobres, frisas da Irlanda contra as invernias, trigo de Castela para socorrer os famintos. Ficou conhecido por "arcebispo santo" pelo exemplo nas calamidades, na peste e na guerra que assolaram Braga no seu pontificado (Rolo, 2000: 84).

Maria, na história dominicana, acompanhou a missão apostólica dos pregadores, orago dos seus conventos: Neves, Graça, Piedade, Mártires, Misericórdia, Vitória, Assunção, Paraíso, Rosário. No séc. XVIII, cerca de dois terços das paróquias de Portugal tinham a confraria do Rosário. A ereção das confrarias do Rosário, do Nome de Jesus (1247) e do Santíssimo Sacramento (anexa à da Basílica da Minerva, em Roma) era reservada ao mestre-geral dos seus pregadores ou seus delegados. Nas igrejas dominicanas, as confrarias não são pergaminhos de arquivo, mas instituições vivas da religiosidade de um povo (Rolo, 2000: 85).

\subsection{Dominicanos: fundação da Ordem dos Pregadores e da sua presença em Portugal}

Carreira (s.d.) transmite-nos que a Ordem Dominicana nasce numa época com um problema muito preocupante para a Igreja Católica - a proliferação dos cátaros, um movimento que se espalhou sobretudo pelo sul de França e Itália, entre os séculos XI e XIV. A pregação surgia como uma necessidade vital para a Igreja, para que a evangelização levasse à conversão dos hereges ou descrentes.

O estudo aprofundado da doutrina estava ao serviço da Igreja e a pregação fundamentada era a ferramenta preferida para levar a palavra aos que mais precisavam de a ouvir. Apesar de fortemente eruditos, ao ponto de a Ordem ser também apelidada de Ordo Doctorum, os pregadores partiam despojados de bens materiais, atitude assumida pelo próprio S. Domingos desde os primórdios.

$\mathrm{O}$ apogeu dos Pregadores (Carreira, s.d.) foi atingido com a entrega do mosteiro de Santa Maria da Vitória, na Batalha, em 1388, quando D. João I assumia o trono. Do mesmo modo, o infante D. Pedro fundaria um convento em Aveiro, em 1423. Neste contexto da nova dinastia de Avis, destaca-se a figura de Fr. Vicente de Lisboa, confessor do rei, reformador da Ordem de S. Domingos em Portugal, e responsável pela fundação do convento de S. Domingos de Benfica (1399). O ano de 1418 representa um marco fundamental na história da Ordem em Portugal: a bula Sacrae religionis, de Martinho V, aprova a Província Portuguesa, autonomizando-a da ibérica. A época áurea da Ordem em Portugal ocorreu no séculpo XVI, através da fundação de mais conventos, do Colégio de S. Tomás, em Coimbra (1566) - o primeiro colégio universitário - e pelo aumento do espólio bibliotecário que alimentava a erudição dos frades. Mesmo a participação de dominicanos na escolha e censura de livros no organismo do Santo Ofício comprovava a sua bem conceituada erudição, uma vez que se exigia um profundo conhecimento da doutrina católica a quem exercesse essa função. Os dominicanos portugueses celebrizaram-se na Europa, onde lecionaram em universidades como Oxford, Paris, Cambridge, Toulouse, Valladolid, Lovaina, entre outras.

A comitiva enviada para representar Portugal no Concílio de Trento era constituída por dominicanos, destacando-se Fr. Bartolomeu dos Mártires. Figura de grande relevo na história da Ordem em Portugal, este frade pregador foi arcebispo de Braga e um importante executor das medidas tridentinas na sua arquidiocese. Este cenário fértil dominicano conheceria um revés durante o período filipino, na medida em que a Ordem assumia um sentimento marcadamente anticastelhano. A decadência viria a acentuar-se no século XVIII, em que a instituição perde alguma autonomia ao ser-lhe imposto, pelo Marquês de Pombal, o nome de Fr. João Mansilha como superior maior, contrariando a autoridade do Capítulo 
Provincial (http://dominicanos.pmeevolution.com/), antecedendo 1834, de Joaquim António de Aguiar, que extinguiu as ordens religiosas de Portugal.

Atualmente, os dominicanos têm casas em Lisboa (Convento de S. Domingos; Casa Nossa Senhora do Rosário no Corpo Santo), Fátima (Convento Nossa Senhora do Rosário); e Porto (Convento de Cristo Rei). Seguindo o trilho do fundador, a Ordem dos Pregadores continua a ter no desenvolvimento intelectual o instrumento privilegiado da conversão. É no estudo aprofundado da doutrina que radica a evangelização e se concretiza a imagem iluminada que S. Domingos legou aos seus companheiros e descendentes espirituais (http://dominicanos.pmeevolution.com/).

\subsection{A devoção dominicana}

Elaboramos uma lista do culto dominicano, sem a pretensão de uma investigação exaustiva, anotando-se a presença nos retábulos das igrejas que fazem parte do itinerário em estudo. As adoções dominicanas, e outras não dominicanas, fruto de uma flexibilidade entrosada em devoções modernas, estão registadas nos templos em estudo: i) devoção mariana - a Senhora do Rosário pontifica em três espaços; Santa Rosa Lima, Santa Luzia, Senhora das Graças e Entrega do Rosário a São Domingos e a Santa Catarina de Sena em dois; a Senhora do Ó num único espaço. São os retábulos colaterais e os laterais que os acolhem, excetuando a Entrega do Rosário a São Domingos e a Santa Catarina de Sena (mor de Ancede). Não foram integradas nas áreas em estudo apenas duas das devoções marianas: Senhora das Neves e Senhora do Paraíso. Das restantes, sucedeu o mesmo com Alberto Magno (doutor da Igreja); Apresentação de Nossa Senhora; Carlos Borromeu (bispo e confessor); e Catarina de Alexandria (mártir). Nas restantes devoções, domina S. Domingos (seis), seguindo-se Francisco Assis e Senhora de Fátima (três); S. Gonçalo de Amarante, Santo António e Senhora do Rosário de Fátima e Pedro Mártir (dois); devoção cristocêntrica, Fr. Bartolomeu dos Mártires, S. Martinho de Tours (Bispo), Santo André (apóstolo), Santa Catarina de Sena, S. Tiago e S. Jacinto (um). Em espaços sacros mais nobres - retábulos-mores -, apenas se destacam: S. Francisco Assis (S. Gonçalo e S. Domingos); Santo André (apóstolo), Ancede; S. Domingos (Mancelos); S. Martinho de Tours (Bispo), Mancelos; S. Gonçalo (capela sob o espaço mor).

Foram introduzidas devoções (nenhuma em retábulo-mor), por razões de estratégia eclesial, de ligação aos franciscanos e de popularidade, entre outras; as restantes conservam-se no Museu de Arte Sacra: Coração de Jesus - Freixo de Baixo, Ancede e Mancelos; Santa Clara - Museu de Arte Sacra; Senhora da Conceição - Freixo de Baixo e Museu de Arte Sacra; Coração de Maria - S. Gonçalo; Senhora das Dores - Mancelos e S. Gonçalo; Divino Salvador, Freixo de Baixo; S. Sebastião, pintura em Mancelos.

\section{A rota dominicana em Amarante e em Baião}

O sentido da proposta desta rota entronca na RR (exceto os templos do centro histórico de Amarante), cuja dinamização é um facto indelével no País ao nível do património arquitetónico, histórico e artístico religioso e civil; uma nota ainda para a relação com as comunidades e todas as atividades que são levadas a efeito ativando, permanentemente, um espaço geográfico, que começou com a região do Sousa, alargou-se ao Tâmega e ao Douro Sul (Cinfães e Resende);

A identidade da RR interliga-se com a organização eclesiástica diocesana e paroquial e com os mosteiros das várias ordens monásticas, fundados ou reconstruídos nos séculos XII e XIII, não correspondendo propriamente à Reconquista, mas antes à reorganização do território. As dioceses dividem-se em paróquias que têm, no Entre-Douro-e-Minho, uma rede muito densa (Rosas, Botelho \& Resende, 2014: 25), razão da riqueza patrimonial existente - arquitetura a artes românicas e adesão às estéticas artísticas posteriores.

Nas devoções da RR imperam, naturalmente, a cristológica e a mariana; a nossa opção dominicana não olvida a importância do beato S. Gonçalo na região e além-fronteiras, apesar de a sua posição nos retábulos de igrejas do Tâmega e Sousa estar circunscrita aos colaterais e laterais; nas capelas, já é mais visível como orago (Rodrigues, 2011: 34-35).

As acessibilidades permitem um futuro sustentável para a $R R$ e restante acervo patrimonial, como a A28, A3, A24, A4, A7, A11, A1, A29, A41, A42. Amarante, como destino turístico, viabiliza a presente proposta e outras que venham a ser projetadas, acrescentando-se a existência de alojamento em Baião. Dois dias são suficientes para cumprir a rota, com visitas e participações complementares a outros segmentos. 


\subsection{Igreja do mosteiro de S. Martinho de Mancelos (Amarante, MIP)}

Mancelos associa-se a Afonso Henriques para controlar social e economicamente a região onde confluíam, já no século XII, vários interesses políticos. A importância atual da sua igreja é revelada pela inclusão na RR, em 2010, altura em que foi elaborada uma proposta de conservação, salvaguarda e valorização do imóvel. Já em 1979 fora definida uma Zona Especial de Proteção em torno do conjunto monástico de Mancelos (Botelho \& Resende, 2014: I, 351; 372-373).

D. João III doou, em 1540, Mancelos aos religiosos de S. Gonçalo de Amarante; Mancelos tornar-se-á, a partir de então, um polo da ação administrativa e evangelizadora dos pregadores amarantinos, tornando-se um dos complexos monásticos mais importantes daquela Ordem, em Portugal. Da campanha barroca resta apenas o retábulo maior dentro do espírito joanino (Botelho \& Resende, 2014: I, 363) - asserção de que discordamos, porque o referido retábulo é "ao estilo" barroco e rococó.

Nos espaços intercolúnios, quatro mísulas com as imagens do padroeiro (S. Martinho de Tours), de S. Francisco de Assis e dos santos dominicanos S. Domingos de Gusmão e S. Gonçalo de Amarante. Na nave, dois altares colaterais e um lateral albergam devoções contemporâneas.

\section{Fig. 1: Rota dominicana Mancelos (Amarante) - Ancede (Baião)}

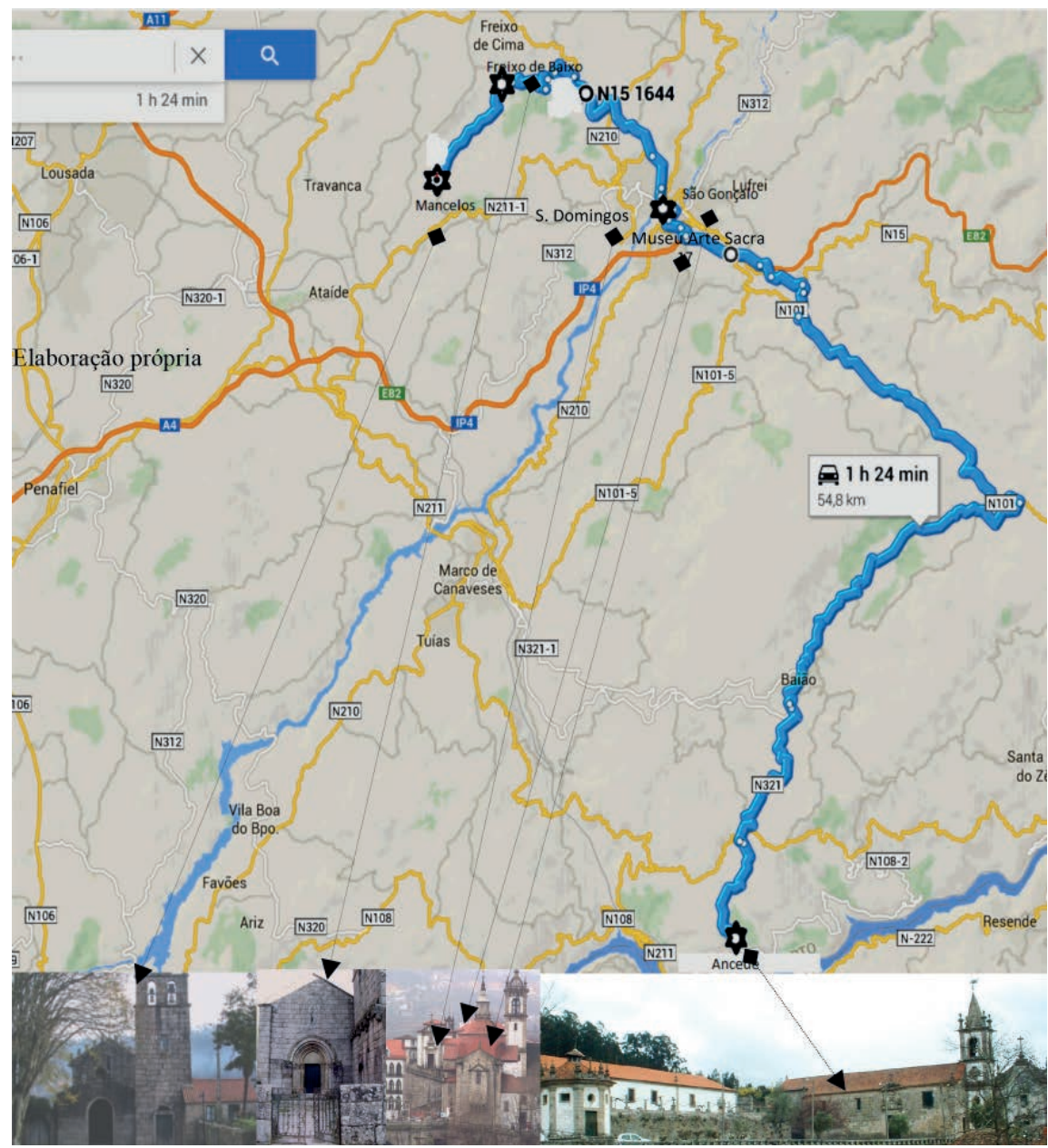

Fonte: Google Maps y Arquivo do autor 
São esculturas datáveis entre as imagens: Virgem do Rosário de Fátima, Sagrado Coração de Jesus e Virgem das Dores. Das cinco pinturas sobre madeira de castanho, destacam-se o mártir S. Sebastião, desnudo e sagitado; a Virgem do Rosário envolta numa orla amendoada formada por rosas, com o Menino ao colo; S. Martinho em cátedra e a representação de Fr. Bartolomeu dos Mártires, cuja biografia nos informa ter estado particularmente ligado à edificação do convento de S. Gonçalo para o qual contribuíram os réditos de Mancelos. Há, ainda, uma em tela de linho retratando, presumivelmente, a cena do milagre designado São Domingos é servido à mesa por anjos, adotando como modelo para a composição a cena da Última Ceia, e acentuando o que S. Domingos de Gusmão procurou assumir, ao longo da sua vida, como imitador de Cristo (Botelho \& Resende, 2014: I, 363-364).

Sintetizando: com a integração na RR, apresenta um portal românico (arquivoltas de transição para o gótico) arco cruzeiro igualmente de transição; na talha: i) retábulo-mor "ao estilo" barroco-rococó"; ii) retábulos colaterais e lateral da Epístola: neoclássico residual.

Fig. 2: Amarante. Igreja do mosteiro de Mancelos

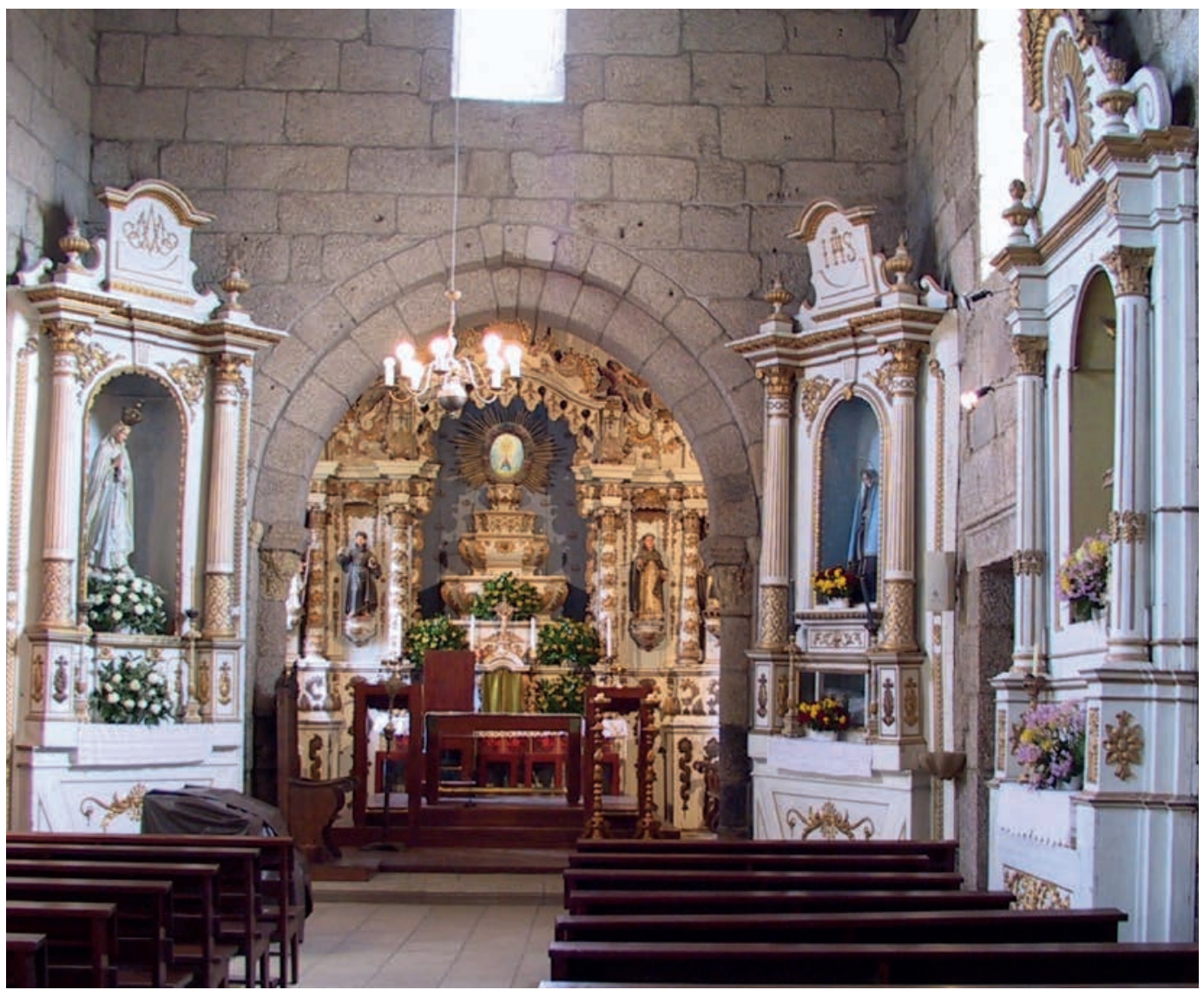

Fonte: arquivo do autor

\subsection{Igreja do mosteiro de S. Salvador de Freixo de Baixo (Amarante, MN)}

A importância deste complexo é similar ao de Mancelos, com um esvaziamento da sua talha, processo comum no Estado Novo, que a ex-DGMEN levou a efeito; em 1971, foi atribuída uma Zona Especial de Proteção à igreja, integrando a RR em 2010, elemento facilitador de obras de conservação e de restauro (Botelho \& Resende, I, 2014: 273). A proximidade de Amarante e a existência de uma recente unidade hoteleira, na freguesia, facilitam a integração na rota que estamos a propor. 
Fig. 3: Amarante. Igreja do Mosteiro de Freixo de Baixo

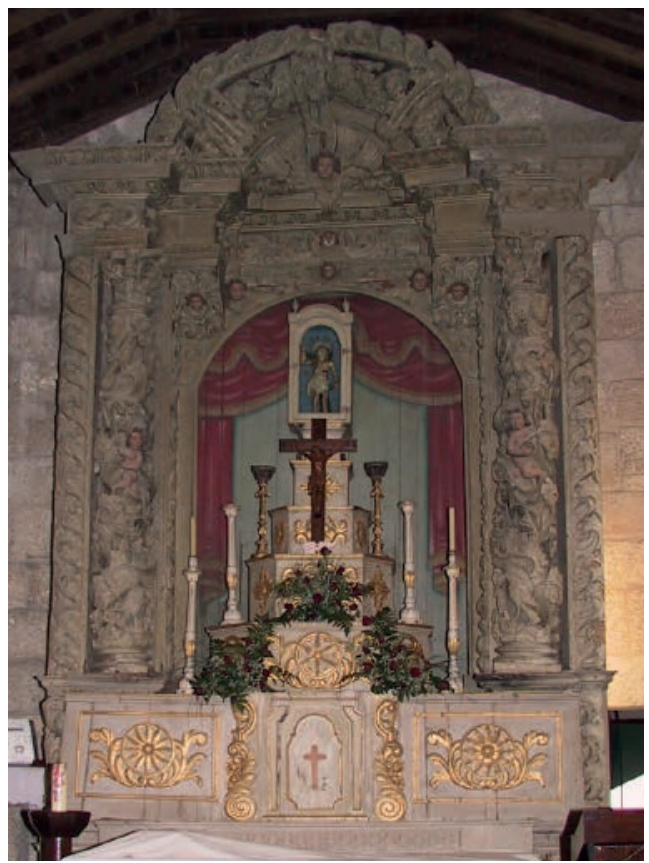

Fonte: arquivo do autor

O percurso histórico deste complexo monástico assemelha-se, em parte, ao seu vizinho de Mancelos (Amarante); no entanto, para a origem dos mosteiros, conhece-se apenas a bula de Calisto II (Botelho \& Resende, I, 2014: 259).

Implantado num vale onde, ainda no século XVIII, circulava uma grande parte do trânsito entre o Minho e Trás-os-Montes, Freixo de Baixo foi, em 1540, anexado (juntamente com o seu curato de São Miguel de Freixo) ao convento dominicano de Amarante. Uma pintura a fresco, colocada em quadro, no lado do Evangelho da nave, trata de uma cena da Epifania do Senhor (Mateus, 2: 1-12), atribuída à oficina liderada pelo Mestre de 1510 responsável, também, por pinturas em S. Mamede de Vila Verde (Felgueiras) e em S. Nicolau de Canaveses (Marco de Canaveses). Paula Bessa (2008: 181-182) citada por Botelho \& Resende (I, 2014: 268) assevera a existência de duas camadas de pinturas sobrepostas, antepondo-se a Epifania a uma mais antiga, ao nivel do rodapé, crendo que datará à volta dos anos 30 de Quinhentos.

No texto da $\mathrm{R} R$ assevera-se que apenas resta hoje parte do retábulo-mor, em talha do estilo barroco nacional, com que se casaram um trono, predela e frontal de altar mais recentes (Botelho \& Resende, 2014: I, 259; 268). O que se terá passado tem a ver com a mobilidade exterior do retábulo-mor, reorganizado de forma anárquica. Não havendo espaço no retábulo para as imagens, o padroeiro, Divino Salvador, assoma em peanha, no lado do Evangelho da capela-mor, o mesmo sucedendo a Santo António; no lado da Epístola, ergue-se Nossa Senhora da Conceição; nos espaços colaterais, igualmente em peanhas, afloram Nossa Senhora de Fátima (Evangelho) e Sagrado Coração de Jesus (Epístola), facto demonstrativo da assunção de devoções não dominicanas. Em síntese: fachada românica (arquivoltas de transição para o gótico), retábulo-mor da fase estilística do barroco nacional, de proveniência exterior; reorganização no remate, entablamento e tribuna; ausência de colunas e arquivoltas; banco e sotobanco da época neoclássica.

\subsection{Núcleo histórico de Amarante: dominância dominicana na fé e na arte erudita}

Facilmente intuímos a importância deste núcleo circunscrito, aqui, ao conjunto monástico de S. Gonçalo e à igreja de S. Domingos, apenas em cota superior ao do primeiro. Há testemunhos das estéticas artísticas renascentistas até ao neoclassicismo. 
Tem as condições de procura na abordagem de um destino turístico, onde se agregam museus (Arte Sacra, Sousa Cardoso, Casa de Pascoaes), a RR, a gastronomia, a doçaria conventual, o vinho verde, as atividades artesanais e uma identidade cultural proeminente nas artes e nas letras. A ponte que atravessa o Tâmega prova a resistência dos militares e das populações aos invasores franceses (segunda tentativa, em 1809).

\subsubsection{Retábulo-mor da igreja do convento de S. Gonçalo}

A rota tem aqui o seu ponto culminante: igreja do convento de S. Gonçalo (MN), igreja de S. Domingos (MIP) e Museu Paroquial de Arte Sacra Dr. Luís Coutinho (Gonçalo \& Coutinho, 2001). Em S. Gonçalo, há espécimes retabulares do barroco nacional ao neoclássico, com exceção do rococó; as fases estilísticas do barroco joanino dominam em S. Domingos, onde apreciamos alguns exemplares de transição joanino-rococó.

Socorremo-nos de Miguel Francisco da Silva, na qualidade de riscador e de executante, para compreendermos o núcleo de Amarante. O retábulo-mor da Sé do Porto, executado por Luís Pereira da Costa (artista portuense) e Miguel Francisco da Silva (lisboeta), entre 1727 e 1729 (Brandão, 1986: 81-87 citado por Ferreira-Alves, 2001: 103) representa a introdução do retábulo joanino na cidade (e irradiação para o Norte), de inspiração do barroco romano, com a marca de Andrea Pozzo (Ferreira-Alves, 2001: 81). As conchas e as cornucópias estilizadas (estriadas e delimitadas com enrolamento em C, são a inspiração para S. Domingos (Amarante) e Bustelo (Penafiel).

Miguel Francisco da Silva optou pela inventividade das conchas e das cornucópias, num percurso longo do barroco joanino, na Sé do Porto e na igreja de S.to Ildefonso (1745) - com o risco de Nasoni. A exceção encontrada resulta de uma parceria com Manuel da Costa Andrade (S. Francisco, Guimarães - 1743) - cornucópias estilizadas no remate do sacrário; sem a estilização, mas com a formatação de cornucópias concebidas em treillage (grade), uma de cada lado do sacrário de Santo Ildefonso, com estilização, e aproximação do que se encontra em Bustelo e em S. Domingos. Miguel Francisco da Silva,

Figs. 4 e 5. Amarante. Retábulo-mor da igreja do convento de S. Gonçalo. Ilhargas da capela-mor da igreja de S. Domingos
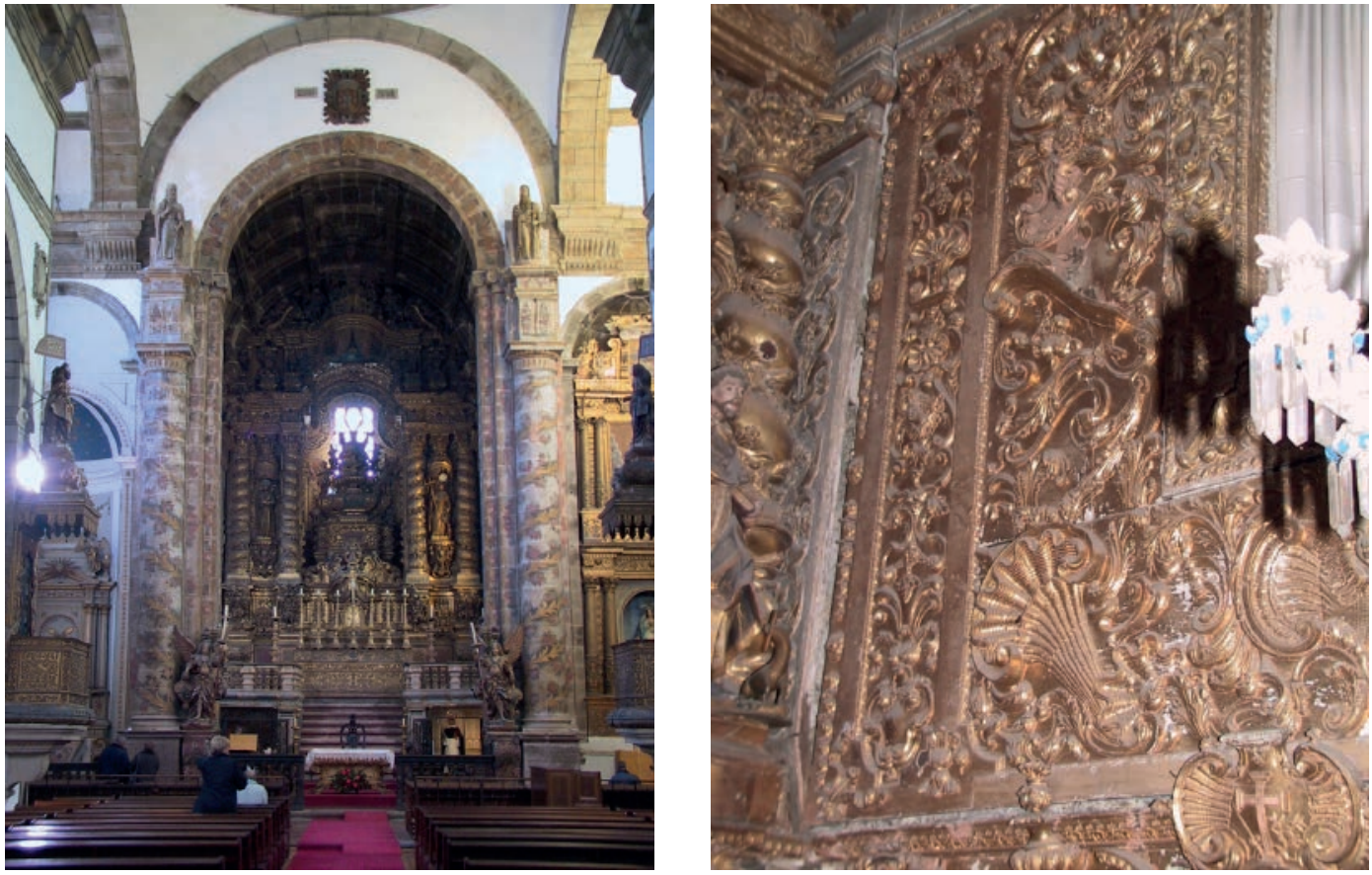

Fonte: arquivo do autor 
José da Fonseca Lima e Manuel da Costa Andrade (com quem consolidou parcerias) são hipóteses para a autoria da talha de S. Domingos.

Como executantes, os últimos: Bustelo (Penafiel) para José da Fonseca Lima e Manuel da Costa Andrade em S. Lourenço de Pias (Lousada) e S. Francisco (Guimarães). Num curto espaço de tempo, de 1742 a 1746, temos trabalhos na região e no centro histórico de Amarante. Daí que a talha de S. Domingos (retábulo-mor e ilhargas da capela-mor) se enquadre na década de 40 do século XVIII (Rodrigues, 2004: I, 293).

Sobre S. Gonçalo, uma informação indica-nos a vistoria de obras diversas no convento, da responsabilidade de Miguel Francisco da Silva (Ferreira-Alves, 2001: 103), sabendo-se que, em 1773, o mestre-pedreiro António Gomes (Sardoeira, 1957: 32-35) foi o autor do alargamento da testeira da capela-mor, estipulando-se a sua revisão pelo arquiteto Miguel Francisco da Silva, dado precioso que permite inferir a época da recepção do atual retábulo-mor. É a altura de propormos um exercício: i) dois pares de colunas com imagens de santos nos intercolúnios, dossel e peanha (elaborada com meninos e festões), em S. Gonçalo, e correlação nas colunas da igreja do mosteiro de Santa Clara (Porto); ii) à coluna salomónica do retábulo-mor da Sé do Porto equivale a de S. Gonçalo, mas invertida, ou seja, as espiras do primeiro terço da Sé (estriadas no bojo) assemelham-se às dos terços superiores de S. Gonçalo; a decoração do primeiro terço, em S. Gonçalo, e dos terços superiores, na Sé, é constituída por meninos - isolados e aos pares - e elementos vegetalistas; iii) são dados que nos libertam para a convicção da presença da escola de Miguel Francisco da Silva no retábulo-mor da igreja do convento de S. Gonçalo, tese partilhada por Nelson Correia Borges (Borges, 1993: 50).

Um apontamento final acerca da iconografia retabulística: na capela-mor, o programa iconográfico dominicano-franciscano - S. Francisco no Evangelho e S. Domingos na Epístola; S. Gonçalo em capela no lado do Evangelho; transepto - SS. mo Sacramento no Evangelho; Sagrado Coração de Maria e Santa Luzia no lado da Epístola; capelas laterais do Evangelho: S. Tiago, Santo António e Senhora do Rosário; capelas laterais da Epístola: Senhora das Dores e S. Jacinto.

Resumindo, a arquitetura da fachada sul contém elementos das coordenadas estilísticas do renascimento, do maneirismo e do protobarroco. Na talha: retábulo-mor do barroco joanino; transepto e capelas laterais do Evangelho e da Epístola: maneirismo, barroco nacional, de transição para o joanino, joanino e neoclássico. Falta apenas o rococó.

\subsubsection{Retábulo-mor da igreja de S. Domingos}

O remate do retábulo-mor de S. Domingos denota uma aproximação a S. Pedro, no qual o arco pleno da tribuna serve de remate, com destaque para quatro anjos, dois deles suportados por volutas e os restantes, em contacto com o próprio arco, seguram uma cartela coroada por uma grinalda. As ilhargas da capela-mor prolongam o continuum desta dinâmica com enrolamentos, conchas com estilização de cornucópia e cabeças aladas. No processo da identificação do retábulo-mor de S. Domingos, visualizamos ornatos nas ilhargas da sua capela-mor - conchas e cornucópias estilizadas, circunscritos por ornatos em C (Reinhardt, 1992: 133). Tudo em bom desempenho e concessão às prescrições com um certo carácter de idealidade.

Avançamos a tese da filiação na escola de Miguel Francisco da Silva: i) pelas conchas e cornucópias estilizadas nas ilhargas da capela-mor, à semelhança da igreja de S. Pedro, nas proximidades; ii) pela estrutura retabular e ornamentação (cabeças aladas).

\subsubsection{Museu de Arte Sacra de S. Gonçalo}

Gonçalo \& Coutinho (2001: 20-25) registam imagens dominicanas (provindas da igreja de S. Gonçalo) e franciscanas (do extinto convento das clarissas), entre outras, de um acervo que contém, também, azulejaria, talha, prataria e vidro em salas distintas: i) sala de paramentaria e alfaias litúrgicas (1. ${ }^{\circ}$ piso); ii) sala das artes decorativas (1. ${ }^{\circ}$ piso); iii) sala de pintura - pinacoteca (1. ${ }^{\circ}$ piso); iv) sala de imaginária dos séculos XVI-XVIII (2..$^{\circ}$ piso); v) sala de imaginária do século XIX (2. ${ }^{\circ}$ piso). 
Figs. 6 e 7: Santa Clara e Santa Rosa Lima
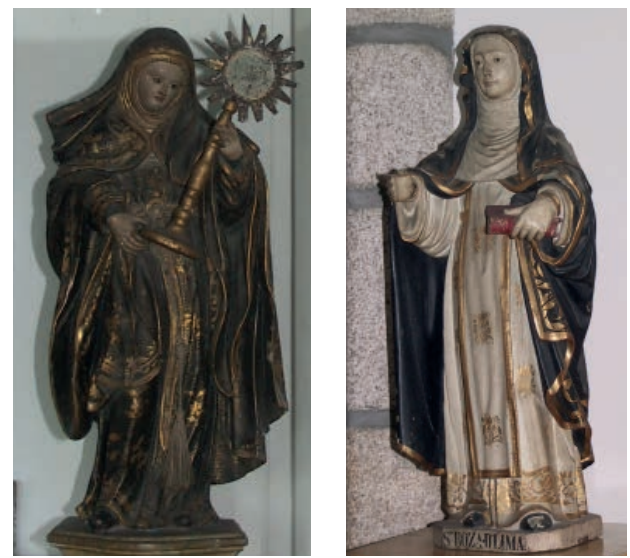

Fonte: arquivo do autor

Destacam-se Santa Clara (franciscana), do extinto convento das clarissas e Santa Rosa Lima (proveniente da igreja do convento de S. Gonçalo).

\subsection{Igreja do convento de S. to André de Ancede (MIP) e capela do Senhor do Bom Despacho (Baião)}

A relativa proximidade a Amarante, a localização sobranceira ao rio Douro, a exuberância da capela do Senhor do Bom Despacho (imaginária e talha de incisão do barroco joanino), as sucessivas campanhas de conservação e restauro do conjunto (entre 2001 e 2015), bem como sondagens arqueológicas, a integração na RR (em 2010), a classificação de MIP (em 2013), a Fundação Eça de Queirós e a existência de uma unidade hoteleira numa freguesia vizinha (Santa Cruz do Douro) permitem augurar o crescimento de visitantes.

O rio Douro e o amparo pontifício permitiram, nos séculos XII, XIII e XIV, que Ancede se tornasse um poderoso centro religioso, rio Douro que permite aos monges de Ancede a rentabilidade dos seus produtos com o burgo do Porto, tornando-se uma quase extensão do termo portuense; no século XVIII, Ancede fazia empréstimos sobre o capital da capela do Bom Despacho (Botelho \& Resende, 2014: I, 103; 105).

A arquitetura da igreja passou por vicissitudes que não estão completamente esclarecidas; a cabeceira é de escala ampla - adequada para ter acolhido um retábulo maneirista - como predizem os caixotões da capela-mor e as naves. A rosácea é o elemento românico remanescente mais significativo, que se difunde, profusamente, no gótico.

Fig. 8: Capela do Senhor do Bom Despacho, igreja e convento de S.to André de Ancede

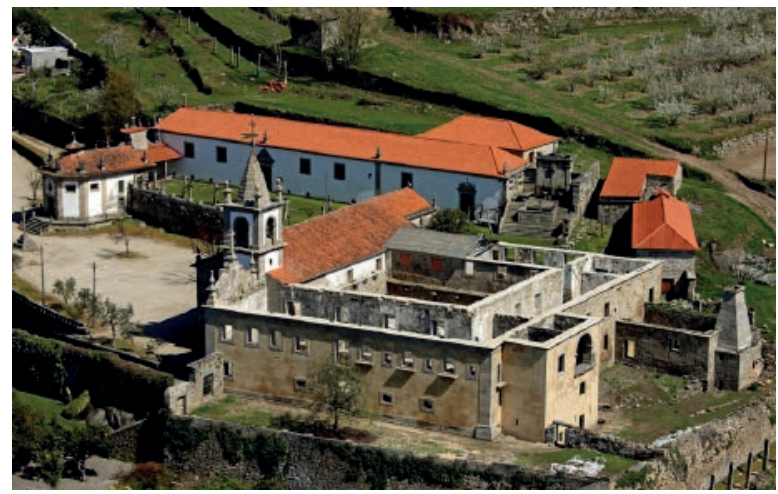

Fonte: arquivo do autor 
Fig. 9: Capelas mor e laterais da igreja do convento

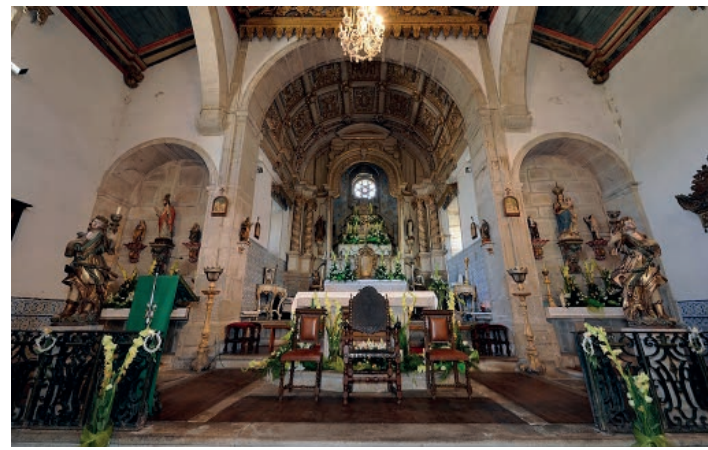

Fonte: arquivo do autor

Em 1559 passa para a Ordem dos Dominicanos - convento de S. Domingos de Lisboa (Botelho \& Resende, 2014: I, 130). Na estrutura do templo destaca-se a austeridade da fachada principal contendo empenas truncadas e portal com apontamentos barrocos; no portal lateral norte, de feição maneirista, interpõe-se, no remate, um nicho barroco com a imagem de S. Domingos.

Na talha, domina o barroco: dois pares de colunas de cada banda, no retábulo-mor, estilo nacional (Santo André e S. Domingos nos intercolúnios), numa composição intervencionada com trono e remate neoclássicos, sinal de reorganização. As capelas colaterais terão sido lugar de retábulos maneiristas; Coração de Jesus (Evangelho) e Senhora do Rosário (Epístola) são as invocações presentes, sem retábulos. O barroco joanino firma-se no sacrário, no púlpito (Epístola), na sanefa; os concheados rococós estão presentes na sanefa do arco cruzeiro onde emerge o brasão dos dominicanos. A cruz processional é do século XIV; a escultura de Santa Luzia e o tríptico de São Bartolomeu são peças datadas do início do século XVI, de origem flamenga; o conjunto de pinturas que invocam os Passos e a Paixão de Cristo são obras da segunda metade do século XVII, assim como o acervo escultórico disperso pela igreja e sacristia, de matriz barroca e executados entre meados do século XVII e os finais do XVIII (http://terralusa.net/index.php?site=213\&sec=part5)

Pertence à RR, registando-se apontamentos maneiristas e barrocos na arquitetura; na capela-mor distinguem-se os caixotões e colunas barrocas; as capelas colaterais são de feição maneirista; há adulteração retabulística em campanhas de substituição, reorganização e de destruição.

A capela do Senhor do Bom Despacho (Lagoa \& Dias, 1991: 467-480), erguida em 1735 - considerada a justaposição da data -, no adro do mosteiro, conserva o retábulo-mor joanino (com acrescentos maneiristas que flanqueiam as pilastras). Programa iconográfico: os mistérios dolorosos e gloriosos da Vida de Cristo; no lado do Evangelho, a Ressurreição, com a legenda: Petit et accipietis

Fig. 10: Capela do Senhor do Bom Despacho

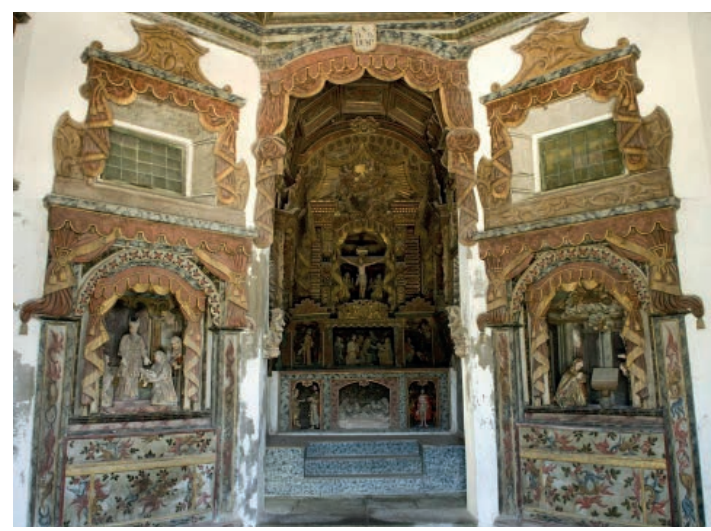

Fonte: arquivo do autor 
(Pedi e recebereis); no lado da Epístola, a Ascensão, com a legenda: Quaerite et invenietis (Procurai e encontrareis). Na parte inferior da tribuna, há uma escultura em terracota, de grande expressividade: a deposição de Jesus no sepulcro, rodeado das santas mulheres e Maria Madalena, José de Arimateia, aos pés e, à cabeceira, Nicodemos. A entrega do Rosário a S. Domingos (no corpo central do retábulo) constitui o apogeu invulgar da obra de arte (http://terralusa.net/index.php? site=213\&sec=part5).

$\mathrm{Na}$ nave octogonal, deparamos com representações cénicas, como se tratasse de um teatro em movimento. Os retábulos laterais exibem um excelente programa barroco joanino ligado, como no retábulo-mor, à espiritualidade dominicana e centrado nos mistérios do Rosário: i) mistérios da alegria (gozosos) - anunciação, visitação; adoração dos reis magos; apresentação no templo. Faltando a apresentação aos doutores, o artista incluiu a circuncisão, a apresentação do Menino aos reis magos; ii) mistérios da dor (dolorosos) - oração e agonia de Jesus no jardim das oliveiras; a flagelação de Nosso Senhor Jesus Cristo; iii) mistérios da glória (gloriosos) - a descida sobre N. ${ }^{\text {a }}$ Senhora e os apóstolos, reunidos no cenáculo. A capela forma, com o mosteiro, o templo principal e o terreiro fronteiro, um conjunto arquitetónico coeso e de inquestionável interesse patrimonial (http://patrimoniocultural.pt/pt/museus-e-monumentos/dgpc).

\section{Conclusão}

O percurso gizado (Mancelos - Ancede) comprova o desempenho dos monges dominicanso na arte, com a dominância do séc. XVIII na talha (barroco nacional e joanino) e na imaginária. O risco erudito está presente no núcleo de Amarante (S. Domingos e S. Gonçalo) interligado com a escola artística da cidade do Porto e com algumas intervenções de artistas de Amarante (pintura). A capela do Senhor do Bom Despacho (Ancede, Baião) é outro exemplo de interpretação invulgar dos mistérios do Rosário, uma predileção dominicana na emissão da sua mensagem evangélica.

Os templos dos conventos de Mancelos, de Freixo de Baixo e de Ancede são o sinal da intervenção do homem depois da colocação de espécimes originais, que conduz vários estudiosos a equívocos, nomeadamente a DGPC quando identifica o retábulo-mor de Mancelos na linha interpretativa do barroco (é ao estilo barroco-rococó), lapso que vai fazendo escola por se tratar de uma instituição que deveria merecer uma elevada fiabilidade.

Dois dias despendidos para este itinerário, acompanhado de informação precisa e pedagógica, valoriza o património religioso cada vez mais procurado e estudado, sustentando a premissa de um turismo religioso emergente. As acessibilidades (auto-estradas), o alojamento de tipologia diversificada, os equipamentos culturais, as oportunidades de turismo de natureza e fluvial (rio Douro), a gastronomia, as atividades artesanais são, entre outras, as potencalidades de dois concelhos da região do Tâmega.

Posteriormente, haverá lugar a um trabalho de inquérito online e entrevistas, como afirmámos na introdução.

\section{Siglas e Acrónimos}

DGEMN - Direção Geral dos Edifícios e Monumentos Nacionais

DGPC - Direção Geral do Património Cultural

DRCN - Direção Regional da Cultura do Norte

MIP - Monumento de Interesse Público (nova designação)

$\mathrm{MN}$ - Monumento Nacional

RR -Rota do Românico

TPNP - Turismo do Porto e Norte de Portugal

TER - Turismo no Espaço Rural

\section{Bibliografia}

Borges, Nelson Correia

1993. "Do Barroco ao Rococó" in Borges, Nelson Correia, dir. de, História da Arte em Portugal, vol. 9. Botelho, Leonor \& Resende, Nuno

2014. Rota do Românico, coord. de Rosas, Lúcia, vol. I. Lousada: Centro de Estudos do Românico e do Território.

Brandão, Domingos de Pinho

1986. Obra de Talha Dourada, Ensamblagem e Pintura na Cidade e Diocese do Porto, III. Porto: Tellos Editora. 
Capela da Senhora do Bom Despacho.

s.d. Em http://terralusa.net/index.php?site=213\&sec=part5 (acessível: 15 setembro 2014).

Carreira, Paula Cristina Ferreira da Costa

s.d. Dominicanos: Breve História da Fundação da Ordem dos Pregadores.

Em http://www.op.org/default.htm (acessível: 2 outubro 2014).

Direção Geral do Património Cultural

s.d. Em http://patrimoniocultural.pt/pt/museus-e-monumentos/dgpc/ (acessível: 15 setembro 2014).

Dominicanos (Os) em Portugal

s.d. Em http://dominicanos.pmeevolution.com/ (acessível: 3 agosto 2014).

Ferreira-Alves, Natália Marinho

2001. A Escola da Talha Portuense e a sua Influência no Norte de Portugal. Lisboa: Edições Inapa.

Gonçalo, Amaro \& Coutinho, Luís

2001. Igrejas de Amarante. São Gonçalo. São Pedro. Nossa Senhora dos Aflitos. Amarante: Paróquia de Amarante (São Gonçalo).

Lagoa, Maria J. \& Dias, J. P

1991. "Ancede: Capela da Senhora do Bom Despacho" in Atas do I Congresso Internacional do Barroco (pp. 467-480). Porto: Reitoria da Universidade do Porto.

Marques, João Francisco

1993. "Franciscanos e Dominicanos Confessores dos Reis Portugueses das duas Primeiras Dinastias. Espiritualidade e Política" in Livro de Atas de Conferência Nacional (pp. 53-60). Em http://hdl.handle. net/10216/8336 (acessível: 13 agosto 2012).

Reinhardt, Ursula

1992. "Achante" in Gruber, Alain - L'Art Décoratif en Europe Classique et Baroque. Paris: Éditions Citadelles et Mazenod.

Rodrigues, J. C. Meneses

2004. Retábulos no Baixo Tâmega e no Vale do Sousa (Amarante, Felgueiras, Marco de Canaveses e Penafiel). Do Maneirismo ao Neoclássico - Séculos XVII - XIX), vol. I. Tese de doutoramento. Porto: FLUP. Em http://hdl.handle.net/10216/14303 (acessível: 2 agosto 2014).

Rodrigues, J. C. Meneses

2011. "Imagens da Devoção Nacional em Retábulos do Baixo Tâmega e do Vale do Sousa". Iconografia Religiosa das Invocações Nacionais. Cultura. Revista de História e Teoria das Ideias, 27, II Série (pp. 25-39). Lisboa: Centro de História da Cultura da UNL, Edições Húmus.

Rolo, Raul A.

2000. "Dominicanos" in Azevedo, Carlos Moreira (Dir.) - Dicionário de História Religiosa de Portugal, vol. II (pp. 82-88.). Rio de Mouro: C. Leitores SA e Centro de Estudos da História Religiosa da Universidade Católica Portuguesa.

Rosas, Lúcia; Botelho, Leonor \& Resende, Nuno

2014. Rota do Românico, coord. de Rosas, Lúcia, vol. I. Lousada: Centro de Estudos do Românico e do Território.

Santos Dominicanos (Todos os). Em http://artereligiao.blogspot.com.br/2011/11/7-de-novembro-todos-os-santos.html (acessível: 12 setembro 2014).

Sardoeira, Albano

1957. "Notícia de alguns artistas que trabalharam em Amarante". Separata do Boletim Douro Litoral, Oitava Série, n. ${ }^{\text {s }}$ III-IV. Porto: (s. e.).

Vieira, João \&, Lacerda, Manuel, coord. de

2010. KIT05 Património Arquitetónico. Edifícios Conventuais Capuchos. Lisboa: IHRU, IGESPAR. Em http: //www.igespar.pt/media/docs/2010/12/22/KIT05.pdf (acessível: 07 agosto 2012).

Recibido:

$22 / 11 / 2017$

Reenviado:

$10 / 04 / 2018$

Aceptado:

$08 / 06 / 2018$

Sometido a evaluación por pares anónimos 